\title{
Hemorrhagic polyps formed like fundic gland polyps during long-term proton pump inhibitor administration
}

\author{
Tsutomu Takeda $^{1} \cdot$ Daisuke Asaoka $^{1} \cdot$ Yuzuru Tajima $^{1,2} \cdot$ Kenshi Matsumoto $^{1}$. \\ Naoto Takeda $^{3}$ - Takahumi Hiromoto ${ }^{1}$ Shoki Okubo ${ }^{1} \cdot$ Hiroaki Saito $^{1}$. \\ Tomonori Aoyama ${ }^{1}$ - Tomoyoshi Shibuya ${ }^{1}$ - Naoto Sakamoto ${ }^{1}$ Mariko Hojo ${ }^{1}$. \\ Taro Osada $^{1} \cdot$ Akihito Nagahara $^{1} \cdot{\text { Takashi } \text { Yao }^{2} \cdot \text { Sumio Watanabe }}^{1}$
}

Received: 7 September 2016/Accepted: 13 June 2017/Published online: 28 June 2017

(c) The Author(s) 2017. This article is an open access publication

\begin{abstract}
We report a rare case of hemorrhagic gastric polyps resulting in anemia during long-term proton pump inhibitor (PPI) administration that endoscopically looked like a fundic gland polyp (FGP). A 44-year-old man presented complaining of anemia and tarry stools. Esophagogastroduodenoscopy (EGD) demonstrated multiple white edematous polyps in the corpus and antrum, which were considered to be FGPs. We attempted endoscopic hemostasis but hemorrhaging increased because of hemorrhagic polyps and vulnerable gastric mucosa. Re-bleeding occurred several times. Polyp resection was performed at 24 polyp sites. We also ceased the administration of PPI. Microscopically, polyps showed characteristics of hyperplasia in the foveolar epithelium, extensions of fundic glands, and edema of the stroma. The proliferation of parietal and chief cells was also observed. Immunohistochemically, aquaporin-4 (AQP4) and KCNQ1-positive parietal cells and dilated mucous glands were found from the basal side to the apical side of the mucosa. These findings were compatible with the development of lesions associated with the long-term administration of PPI. EGD revealed an improvement in the vulnerability of gastric mucosa and the development of polyps, with no further gastric polyps observed 1 year after discharge. Bleeding from polyps resembling FGPs is generally rare, with
\end{abstract}

Tsutomu Takeda

t-takeda@juntendo.ac.jp

1 Department of Gastroenterology, Juntendo University School of Medicine, Tokyo, Japan

2 Department of Human Pathology, Juntendo University School of Medicine, Tokyo, Japan

3 Department of General Medicine, Juntendo University School of Medicine, Tokyo, Japan indications that long-term PPI administration may induce such bleeding.

Keywords Fundic gland polyp · Long-term proton pump inhibitor therapy $\cdot$ Bleeding - Selective serotonin reuptake inhibitors $\cdot$ Aquaporin-4 $\cdot$ KCNQ1

\section{Introduction}

Proton pump inhibitors (PPI) are important drugs used worldwide as first-line drugs for gastroesophageal reflux disease and non-steroidal anti-inflammatory drug-induced ulcer treatment. However, in recent years, the increased risk of gastric polyps during long-term PPI administration has been a growing concern. In this case report, we describe rare hemorrhagic gastric polyps, resulting in anemia during long-term PPI administration, which formed into fundic gland polyps (FGPs) as determined endoscopically, but which were not typical for FGP as determined by pathology.

\section{Case report}

A 44-year-old man presented to hospital complaining of anemia and tarry stools. He had previously reported heartburn symptoms 10 years previously. Since a subsequent esophagogastroduodenoscopy (EGD) did not show any abnormalities, he was diagnosed with non-erosive reflux esophagitis and the oral administration of $15 \mathrm{mg}$ lansoprazole was initiated once a day. He also had a history of hypertension and depression, therefore paroxetine hydrochloride hydrate $(20 \mathrm{mg} /$ day for 7 years $)$, and 
amlodipine besilate $(10 \mathrm{mg} /$ day $)$ had been administered for several years.

He was brought to our hospital because he was diagnosed with anemia (hemoglobin $[\mathrm{Hb}] 8.0 \mathrm{~g} / \mathrm{dL}$ ) during a medical checkup. During EGD, whitish, edematous multiple polyps in the antrum and corpus of the stomach without hemorrhages were noted, which made us suspect FGPs according to endoscopic findings, and a biopsy was subsequently performed (Fig. 1a). Pathological findings revealed dilated and proliferated fundic glands with foveolar hyperplasia. A colon endoscopy did not reveal any abnormalities. However, the patient complained of general fatigue and a large amount of tarry stools was observed. The patient was admitted to our hospital 8 days after his initial EGD. The patient's family history was unremarkable and he did not have a history of allergies. His alcohol consumption was around $350 \mathrm{~mL} /$ day of beer for 20 years. A blood test showed iron deficiency anemia. Serum anti- $H$. pylori antibody level and antigen in stool were within the normal range. The anti-gastric parietal cell antibody test was also negative (Table 1). Computed tomography did not identify any cause for gastrointestinal bleeding. The patient underwent a capsule endoscopy, which did not reveal any abnormalities in the small intestine, although a large amount of black residue was observed in the stomach. EGD revealed multiple polyps and mild oozing was observed from the polyps and gastric mucosa (Fig. 1b). We tried to perform endoscopic hemostasis by using hemostatic forceps in the soft coagulation mode, but the observed hemorrhaging increased. Because the gastric mucosa was vulnerable to further hemorrhage and the oozing still persisted, we resected three bleeding polyps. The patient progressed satisfactorily and he was temporarily discharged. Two weeks after discharge, the patient was rehospitalized with tarry stools. EGD revealed coagula in the stomach, and multiple polyps in the corpus were observed to be hemorrhagic (Fig. 1c, d). Endoscopic mucosal resection and polypectomy were performed at 21 sites. Furthermore, we stopped the administration of a PPI. Microscopically, characteristics of 20 polyps in the body of the stomach were almost same. Significant cystic dilatation of glands was observed. Polyps showed characteristics of hyperplasia of the foveolar epithelium, extended fundic glands and edema of the stroma, suggesting lesions that

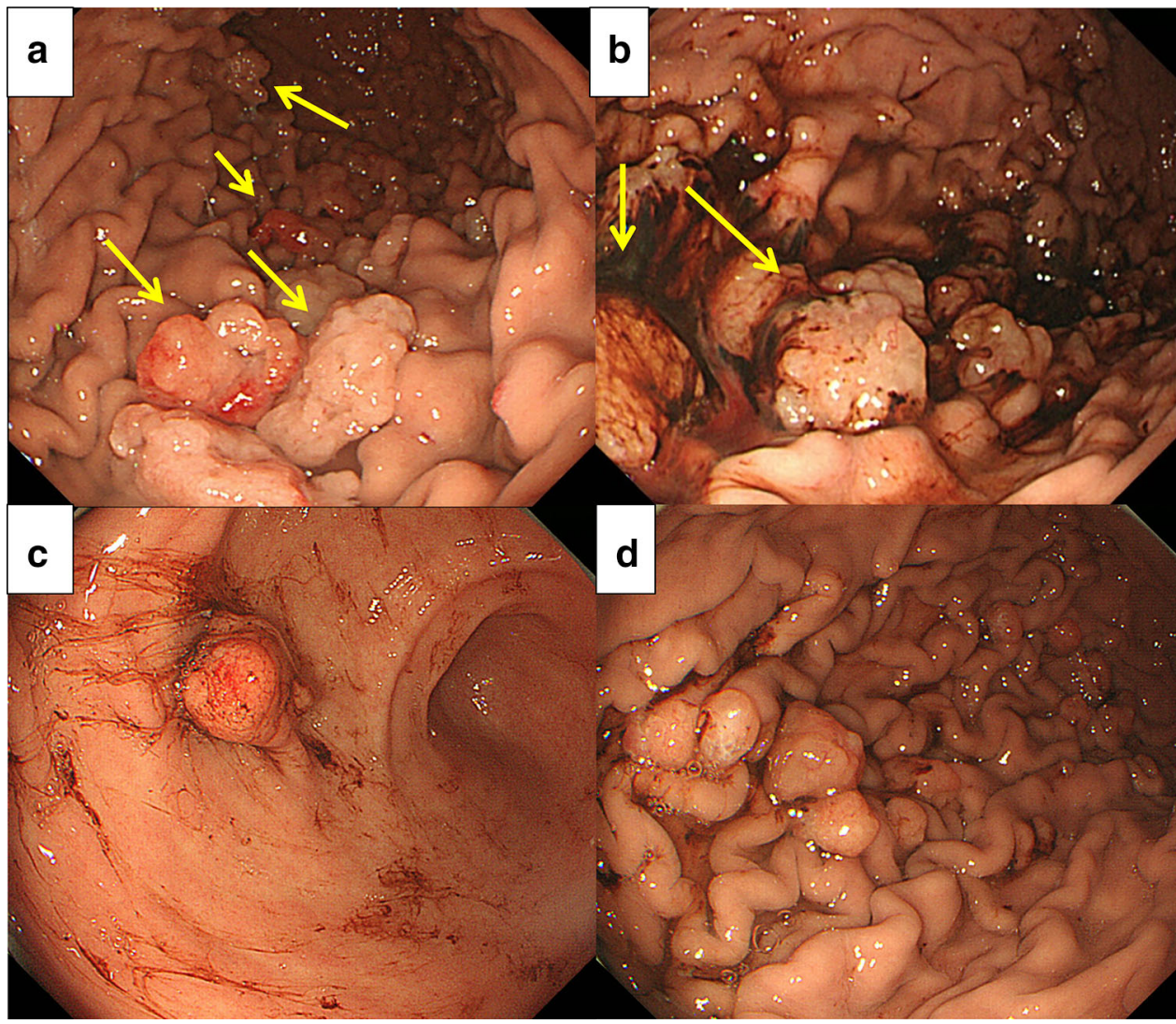

Fig. 1 Esophagogastroduodenoscopic findings. a Multiple white edematous polyps (arrows) were observed in the corpus and antrum, which were considered to be fundic gland polyps (FGPs) as determined endoscopically before admission. b Esophagogastroduodenoscopy (EGD) revealed mild oozing from polyps of the gastric corpus (arrows) after admission. c EGD findings at the time of readmission: a reddish, hemorrhagic polyp was observed in the antrum, together with coagula. d Coagula were observed in the stomach, and multiple polyps in the corpus were hemorrhagic 
Table 1 Laboratory data on admission

\begin{tabular}{|c|c|}
\hline \multicolumn{2}{|l|}{ Hematology } \\
\hline WBC & $6300 / \mu \mathrm{L}$ \\
\hline $\mathrm{RBC}$ & $413 \times 10^{4} / \mu \mathrm{L}$ \\
\hline $\mathrm{Hb}$ & $7.6 \mathrm{~g} / \mathrm{dL}$ \\
\hline $\mathrm{Ht}$ & $27.3 \%$ \\
\hline Plt & $25.6 \times 10^{4} / \mu \mathrm{L}$ \\
\hline \multicolumn{2}{|l|}{ Coagulation } \\
\hline PT & $76.0 \%$ \\
\hline APTT & $37.6 \mathrm{~s}$ \\
\hline \multicolumn{2}{|l|}{ Blood chemistry } \\
\hline $\mathrm{TP}$ & $7.2 \mathrm{~g} / \mathrm{dL}$ \\
\hline Alb & $4.6 \mathrm{~g} / \mathrm{dL}$ \\
\hline T-Bil & $0.35 \mathrm{~g} / \mathrm{dL}$ \\
\hline AST & $14 \mathrm{IU} / \mathrm{L}$ \\
\hline ALT & $13 \mathrm{IU} / \mathrm{L}$ \\
\hline ALP & $174 \mathrm{IU} / \mathrm{L}$ \\
\hline LDH & $179 \mathrm{IU} / \mathrm{L}$ \\
\hline$\gamma$-GTP & $31 \mathrm{IU} / \mathrm{L}$ \\
\hline $\mathrm{ChE}$ & $324 \mathrm{U} / \mathrm{L}$ \\
\hline BUN & $10 \mathrm{mg} / \mathrm{dL}$ \\
\hline Cre & $0.81 \mathrm{mg} / \mathrm{dL}$ \\
\hline $\mathrm{Na}$ & $143 \mathrm{mmol} / \mathrm{L}$ \\
\hline $\mathrm{K}$ & $3.8 \mathrm{mmol} / \mathrm{L}$ \\
\hline $\mathrm{Cl}$ & $105 \mathrm{mmol} / \mathrm{L}$ \\
\hline Glu & $103 \mathrm{mg} / \mathrm{dL}$ \\
\hline $\mathrm{Fe}$ & $19 \mu \mathrm{g} / \mathrm{dL}$ \\
\hline TIBC & $551 \mu \mathrm{g} / \mathrm{dL}$ \\
\hline Ferritin & $4 \mathrm{ng} / \mathrm{dL}$ \\
\hline $\mathrm{HbA} 1 \mathrm{c}$ & $5.6 \%$ \\
\hline Gastrin & $89 \mathrm{pg} / \mathrm{mL}$ \\
\hline \multicolumn{2}{|l|}{ Tumor marker } \\
\hline CEA & $2.0 \mathrm{ng} / \mathrm{mL}$ \\
\hline CA19-9 & $11 \mathrm{U} / \mathrm{mL}$ \\
\hline \multicolumn{2}{|l|}{ Serological test } \\
\hline CRP & $0.0 \mathrm{mg} / \mathrm{dL}$ \\
\hline HBsAg & $(-) \mathrm{U} / \mathrm{mL}$ \\
\hline HCVAb & $(-)$ \\
\hline Hp-IgG & $<3 \mathrm{U} / \mathrm{mL}$ \\
\hline Anti-parietal cell antibody & $(-)$ \\
\hline Hp antigen in stool & $(-)$ \\
\hline
\end{tabular}

differed from typical FGPs (Fig. 2-1). Together with hyperplasia of the foveolar epithelium and extended mucous glands, the proliferation of parietal and chief cells were also observed, but not parietal cell protrusion or inflammatory cell infiltration. Apoptotic bodies were detected in the boundary region between fundic and neck mucous glands (Fig. 2-2). Crypt epithelial cells
(MUC5AC) were mainly observed superficially and cervical mucous cells (MUC6) were observed beneath the crypt epithelium. Fundic glands were positive for $\mathrm{H}+/ \mathrm{K}+-$ ATPase, and showed a proliferation of predominantly parietal cells. Only a very slight accumulation of chromogranin A staining was found, and enterochromaffin-like (ECL) cells were not detected. Few positive cells were found by Ki67 staining and polyps lacked dysplasia (Fig. 2-3). Aquaporin-4 (AQP4) and KCNQ1-positive parietal cells and dilated mucous glands were found from the basal side to the apical side of the mucosa. The extension of the distribution of AQP4 and KCNQ1-positive cells toward the apical side of the fundic glands was observed (Fig. 2-4). Overexpression of gastrin receptors was not detected. A reddish polyp in the antrum showed infiltration of inflammatory cells and it was similarpathologically to inflammatory polyp. Gastrin overexpression was not observed in the antral polyp immunohistochemically (Fig. 2-4).

The patient was discharged under continued selective serotonin reuptake inhibitors (SSRIs) administration and has been making satisfactory progress in the outpatient department ever since. EGD showed few gastric polyps 1 month after discharge. The serum gastrin level after PPI withdrawal maintained within the normal range $(120 \mathrm{pg} / \mathrm{mL})$. The vulnerability of gastric mucosa had improved and gastric polyps were not observed 1 year after discharge (Fig. 3).

\section{Discussion}

We report herein a case of hemorrhagic gastric polyps, which were pathologically characterized by both hyperplastic and FGPs during long-term PPI administration, although they showed a morphology similar to FGPs as determined endoscopically. Of the polyps generally found during long-term PPI administration, FGPs are the most common $[1,2]$. According to previous research in Japan [3], FGPs were found in $13.6 \%$, and hyperplastic polyps in $8.9 \%$ of patients during long-term PPI administration.

However, one group reported that FGPs were not induced by PPI therapy [4]. Although the mechanism whereby PPI administration causes FGPs is unknown in detail, a relationship with Helicobacter pylori negative patients has been reported [5]. Tsuchigame et al. reported that FGPs were present in the region blackened by congo red spray and it was considered that FGPs were observed in stomachs with less atrophy [6]. In the present case, a patient who received longterm PPI administration, $H$. pylori was negative and there was no gastric atrophy, therefore $H$. pylori negative may be associated with the FGP-like lesion. Elevated blood gastrin levels are also assumed to cause hyperplastic polyps. Gastrin has a mucosal proliferative effect that enhances the effects of 
Fig. 21 Pathological findings of resected polyps that looked like fundic gland polyp (hematoxylin \& eosin [HE] staining, loupe image). Polyps showed characteristics of hyperplasia of the foveolar epithelium, extended fundic glands and edema of the stroma. 2 Characteristics of pathological findings of resected polyps that looked like fundic gland polyp (hematoxylin \& eosin [HE] staining). Mixed with hyperplasia of foveolar epithelium and extended mucous glands $(A)$, the proliferation of parietal and chief cells was also observed $(B)$, but not parietal cell protrusion or inflammatory cell infiltration $(C)$. Apoptotic bodies were detected in the boundary region between fundic and neck mucous glands $(D) . \mathbf{3}$ Immunohistochemistry for MUC5AC, MUC6, $\mathrm{H}^{+} / \mathrm{K}^{+}$. ATPase, pepsinogen I, Ki-67. Crypt epithelial cells

(MUC5AC) were mainly observed superficially, and cervical mucous cells (MUC6) were observed beneath the crypt epithelium. Fundic glands were positive for $\mathrm{H}+/ \mathrm{K}+$-ATPase, and showed proliferation of predominantly parietal cells. Few Ki67 positive cells were found. 4 Immunohistochemistry for aquaporin-4, KCNQ1, gastrin and gastrin receptor. Aquaporin-4 (AQP4) and KCNQ1-positive parietal cells and dilated mucous glands were found from the basal side to the apical side of the mucosa. The extension of the distribution of AQP4 and KCNQ1-positive cells toward the apical side of the fundic glands were observed. Overexpression of gastrin receptors was not detected. Gastrin overexpression was not observed in the antral polyp

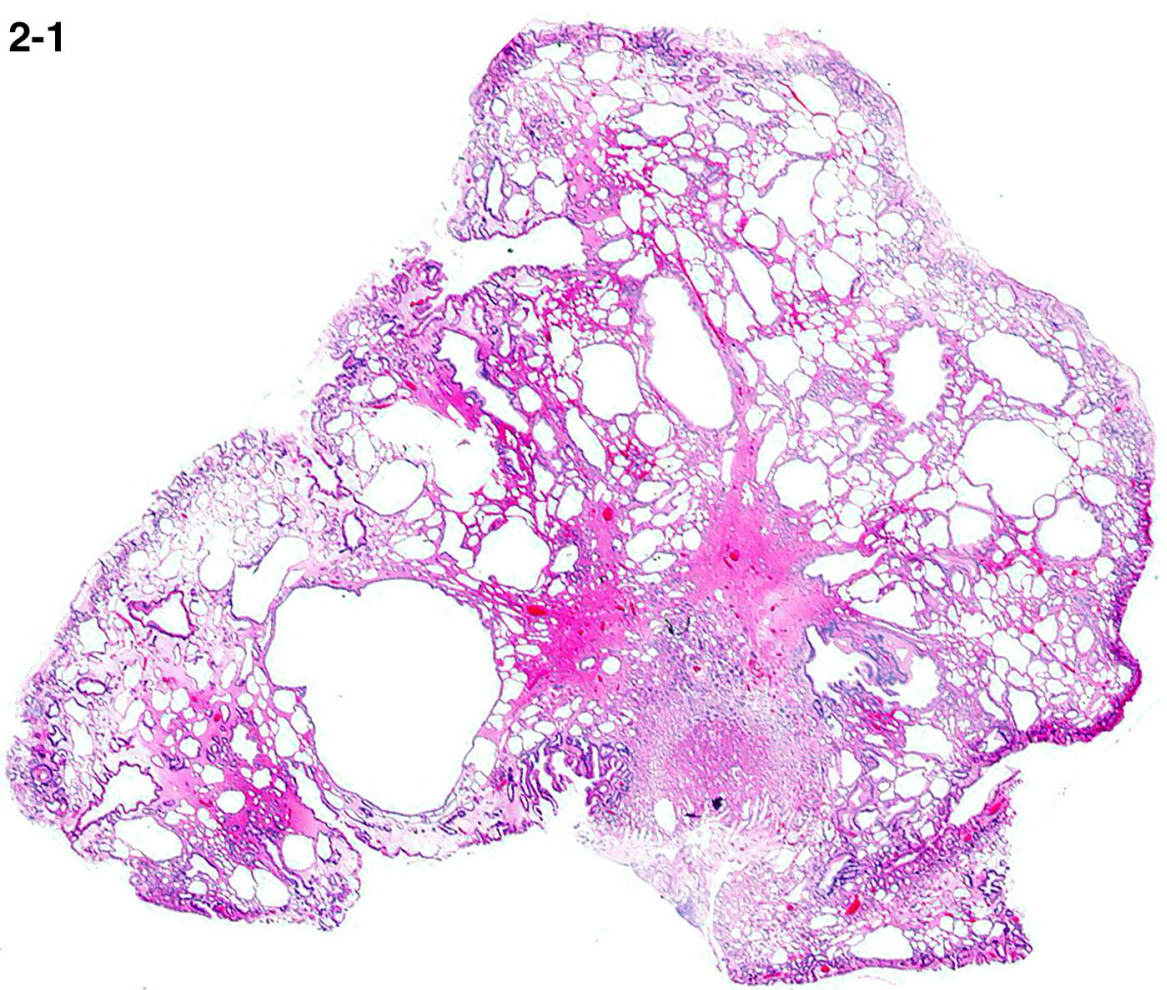

2-2

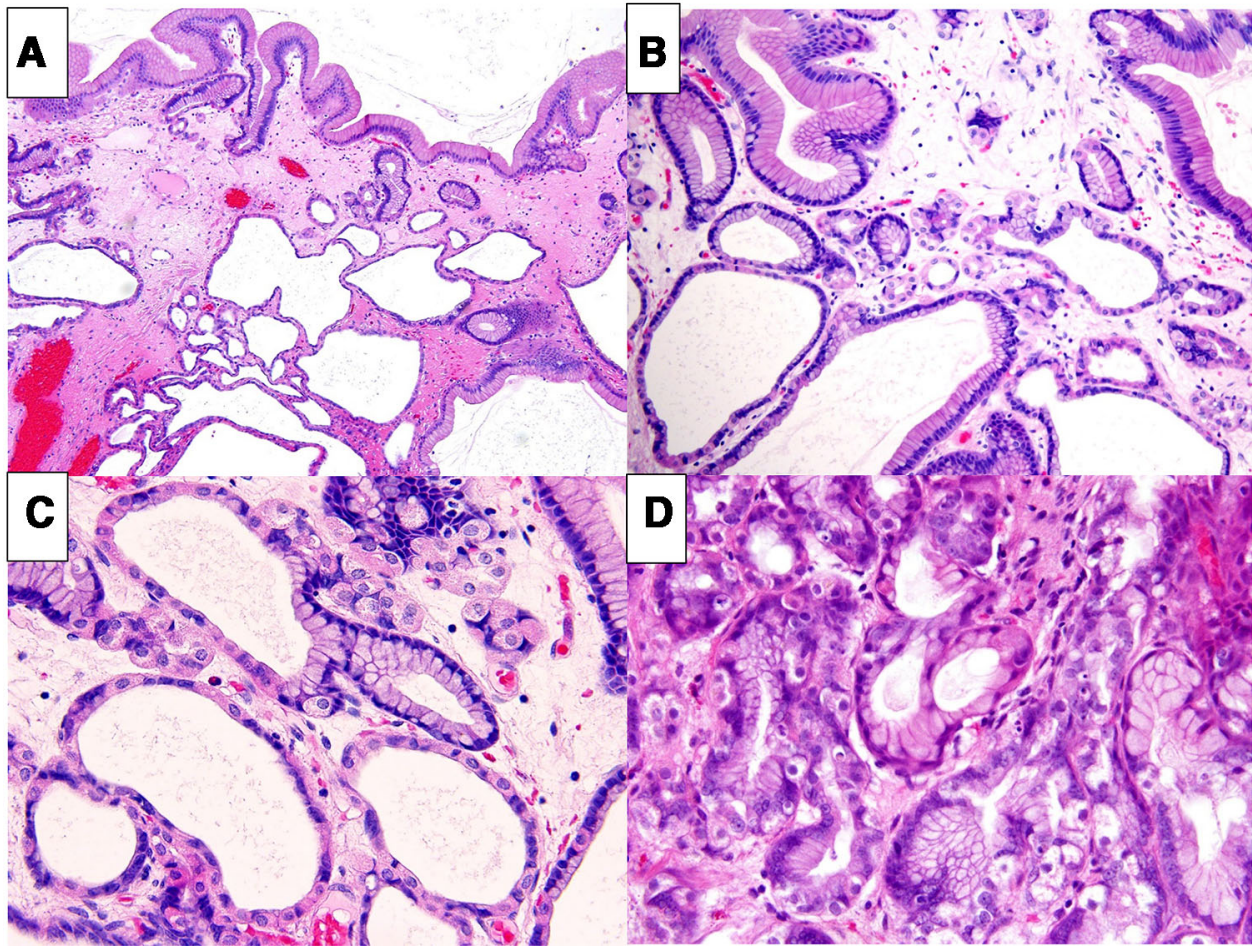

growth factors, such as those of the epidermal growth factor (EGF) and tumor growth factor-alpha (TGF- $\alpha$ ) families, and promotes the growth of crypt epithelial cells [7]. In the present case, a significant decrease in multiple gastric polyps was observed immediately after PPI withdrawal 1 month after discharge, which highlights strongly how PPIs are suspected to cause gastric polyps. PPI administration for a year or more increased the risk of occurrence of polyps significantly, which further increased as the administration term lengthened [8]. 
Fig. 2 continued

2-3
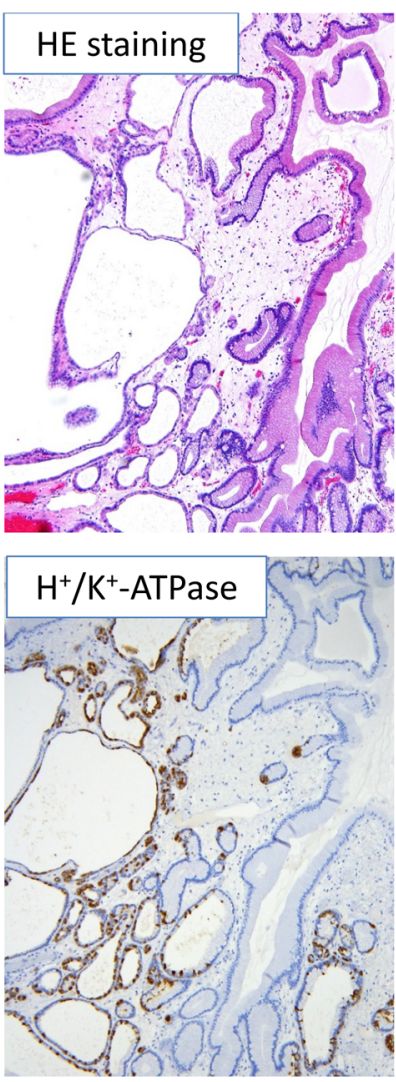

2-4

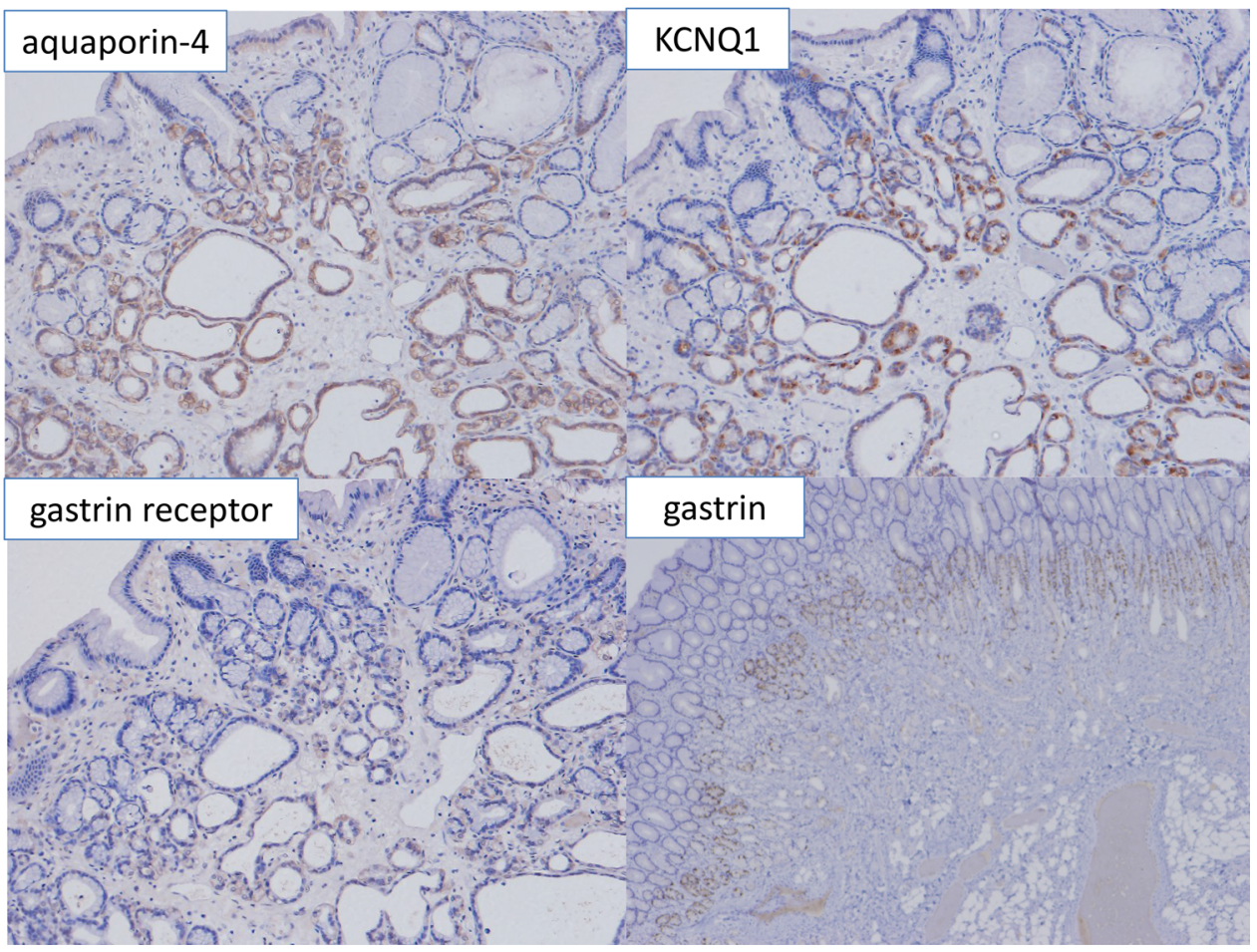

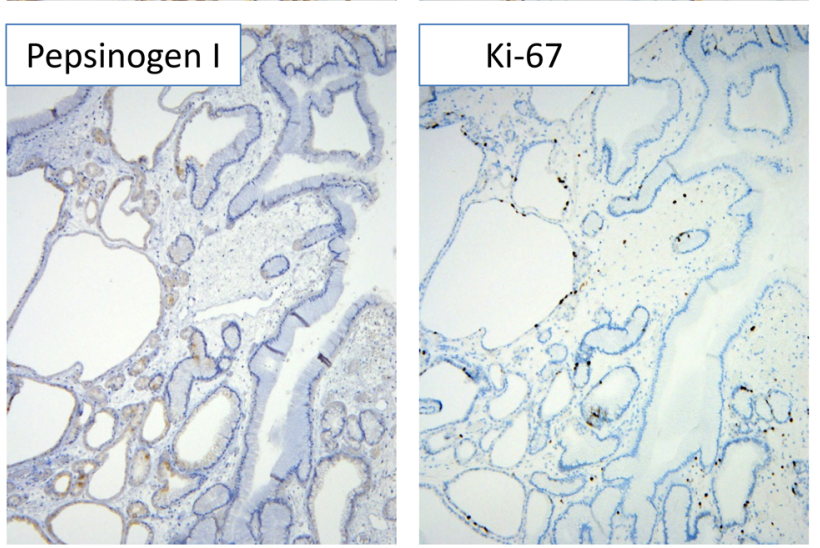
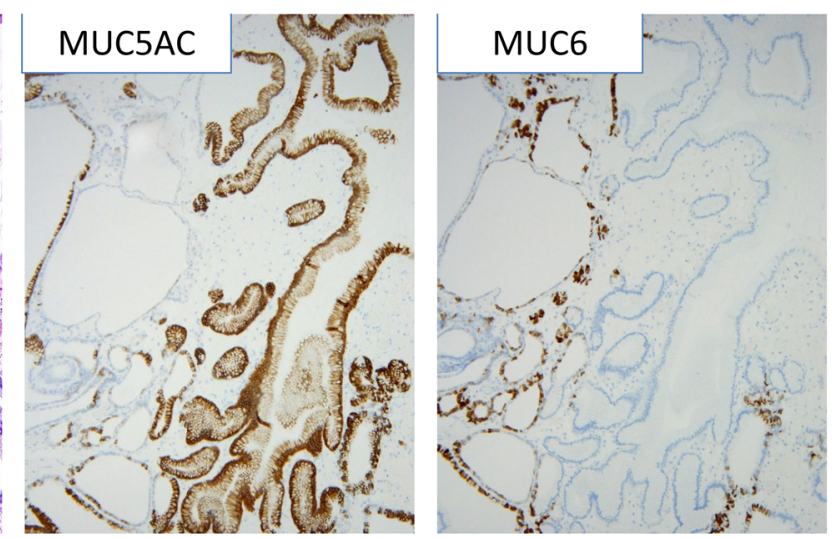


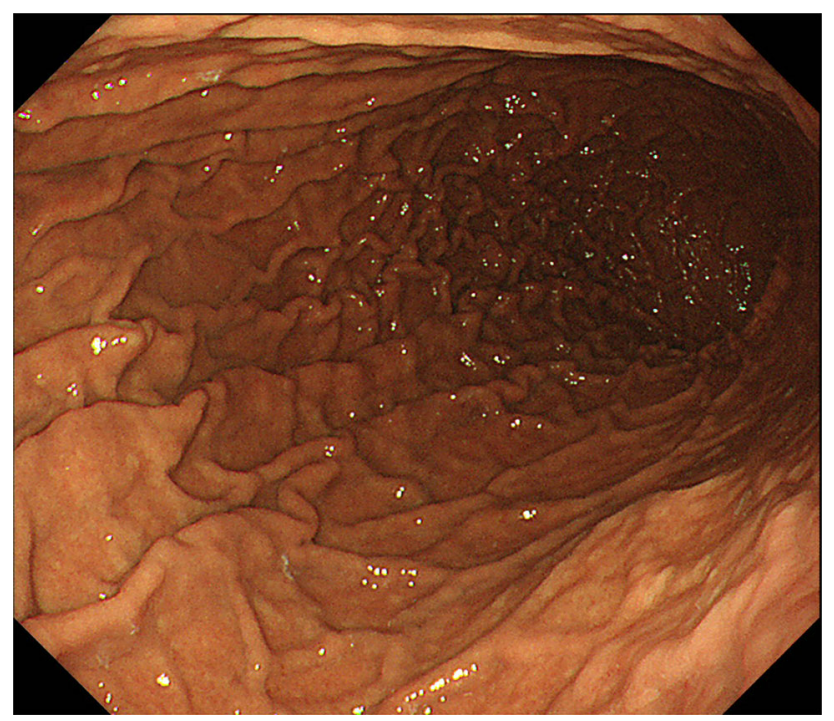

Fig. 3 Esophagogastroduodenoscopic findings 1 year after discharge. Gastric polyps were not observed and the vulnerability of gastric mucosa had improved

The histopathological changes most commonly observed during PPI administration were parietal cell protrusion/ parietal cell hyperplasia, edema of stroma and cystic dilation of the fundic gland duct [9]. In this case, hyperplasia of parietal cells was not found, corresponding with the results of a previous report [9]. Bleeding from multiple FGPs was suspected from endoscopic examination, but pathological tests revealed that polyps consisted of the mixed hyperplasia of foveolar epithelium, and cystic dilatation of fundic glands. Edema of the stroma and extended fundic glands was also observed. Recently some investigators reported the association between acid suppression by PPI and gastric polyps with water channel aquaporin-4 and potassium channel KCNQ1 expression. We performed the immunohistochemical examination of aquaporin-4 (AQP4) and KCNQ1. AQP4 and KCNQ1-positive parietal cells, and dilated mucous glands were found broadly from the basal side to the apical side of the mucosa. The extension of the distribution of AQP4 and KCNQ1-positive cells toward the surface of the fundic glands was observed according to the previous report $[10,11]$. These findings differed from the usual FGPs, and were thought to be lesions associated with long-term PPI administration. The serum gastrin level was not increased from that measured upon admission and also immunohistochemical expression of gastrin and gastrin receptors on these polyps was not increased, which suggests that polyp development or growth was not associated with a gastrin-dependent pathway. Lee reported the importance of apoptosis in the histopathology of drug related lesions [12]. In this case, a patient who received long-term PPI administration, apoptotic bodies were detected between fundic and neck mucous glands. Therefore, the appearance of apoptotic bodies suggests drug related mucosal change and pathogenesis of the FGP-like lesion.

This case was characterized by the relative difficulty of treatment because of hemorrhagic activity. In this case, rebleeding occurred many times after polyp resections, and no clear reasons for the observed hemorrhagic activity have been identified as yet. However, polyp resections combined with hyperplastic components may have led to such hemorrhagic activity. It has been suggested that with regard to hemorrhaging, the long-term administration of PPI should be discontinued. In recent years, a relationship between SSRIs and gastrointestinal bleeding has been found: it is thought that platelet aggregation can be reduced by decreasing the serotonin level of platelets [13]. However, our department previously found that SSRIs did not increase the risk of upper gastrointestinal mucosal damage and gastric polyps as determined endoscopically [14]. Since the development of FGPs and hyperplastic polyps due to the long-term SSRI administration has not been reported, the cause of bleeding in this case may be a reduction of platelet aggregation due to SSRI administration. As for the causes of hemorrhagic gastric mucosa and polyps, we suggest that hyperplasia of foveolar glands may lead to membrane vulnerability and that long-term SSRI administration is involved in hemorrhagic mucosa.

In summary, we experienced a case in which bleeding from polyps in the form of fundic glands during the longterm administration of PPIs was treated by endoscopic resection. Based on the case presented here, it is rare to bleed from polyps that resemble FGPs, but it may be that the long-term administration of PPIs may induce such bleeding. Further pathological investigations will be needed on polyps during long-term PPI administration.

\section{Compliance with ethical standards}

Conflict of interest This work was supported in part by a Grant-inAid for General Scientific Research from the Ministry of Education, Science, Sports, and Culture (\#26460428 to T. Yao), Tokyo, Japan.

Open Access This article is distributed under the terms of the Creative Commons Attribution 4.0 International License (http://crea tivecommons.org/licenses/by/4.0/), which permits unrestricted use, distribution, and reproduction in any medium, provided you give appropriate credit to the original author(s) and the source, provide a link to the Creative Commons license, and indicate if changes were made.

\section{References}

1. Graham JR. Gastric polyposis: onset during long-term therapy with omeprazole. Med J Aust. 1992;157:287-8.

2. Jalving M, Koornstra JJ, Wesseling $\mathrm{J}$, et al. Increased risk of fundic gland polyps during long-term proton pump inhibitor therapy. Aliment Pharmacol Ther. 2006;24:1341-8. 
3. Hongo M, Fujimoto K, Gastric Polyps Study Group. Incidence and risk factor of fundic gland polyp and hyperplastic polyp in long-term proton pump inhibitor therapy: a prospective study in Japan. J Gastroenterol. 2010;45:618-24.

4. Vieth M, Stolte M, et al. Fundic gland polyps are not induced by proton pump inhibitor therapy. Am J Clin Pathol. 2001;116: 716-20.

5. Shand AG, Taylor AC, Banerjee M, et al. Gastric fundic gland polyps in south-east Scotland: absence of adenomatous polyposis coli gene mutations and a strikingly low prevalence of Helicobacter pylori infection. J Gastroenterol Hepatol. 2002;17: 1161-4.

6. Tsuchigame T, Saito R, Ogata Y, et al. Clinical evaluation of gastric fundic gland polyps without familial polyposis coli. Abdom Imaging. 1995;20:101-5.

7. Dockray GJ. Gastrin and gastric epithelial physiology. J Physiol. 1999;518:315-24.

8. Hollingworth S, Duncan EL, Martin JH. Marked increase in proton pump inhibitors use in Australia. Pharmacoepidemiol Drug Saf. 2010;19:1019-24.
9. Cats A, Schenk BE, Bloemena E, et al. Parietal cell protrusions and fundic gland cysts during omeprazole maintenance treatment. Hum Pathol. 2000;31:684-90.

10. Matsuzaki J, Suzuki H, Minegishi Y, et al. Acid suppression by proton pump inhibitors enhances aquaporin-4 and KCNQ1 expression in gastric fundic parietal cells in mouse. Dig Dis Sci. 2010;55:3339-48.

11. Fukuhara S, Matsuzaki J, Tsugawa H, et al. Mucosal expression of aquaporin-4 in the stomach of histamine type 2 receptor knockout mice and Helicobacter pylori-infected mice. J Gastroenterol Hepatol. 2014;29:53-9.

12. Lee FD. Importance of apoptosis in the histopathology of drug related lesions in the large intestine. J Clin Pathol. 1993;46:118-22.

13. Anglin R, Yuan Y, Moayyedi P, et al. Risk of upper gastrointestinal bleeding with selective serotonin reuptake inhibitors with or without concurrent nonsteroidal anti-inflammatory use: a systematic review and meta-analysis. Am J Gastroenterol. 2014;109:811-9.

14. Itatsu $T$, Nagahara A, Hojo $M$, et al. Use of selective serotonin reuptake inhibitors and upper gastrointestinal disease. Intern Med. 2011;50:713-7. 